\title{
Sensitive amperometric determination of hydrazine using a carbon paste electrode modified with silver-doped zeolite $L$ nanoparticles
}

\author{
NEDA SALEK GILANI ${ }^{1}$, SEYED NASER AZIZI ${ }^{1, *}$ and SHAHRAM GHASEMI ${ }^{2}$ \\ ${ }^{1}$ Analytical Division, Faculty of Chemistry, University of Mazandaran, Babolsar 47416-95447, Iran \\ ${ }^{2}$ Faculty of Chemistry, University of Mazandaran, Babolsar 47416-95447, Iran
}

MS received 14 March 2016; accepted 8 June 2016

\begin{abstract}
Silver-loaded nanozeolite-L-modified carbon paste electrode (Ag/L-CPE) was used as a novel sensing platform for enhanced electrocatalytic oxidation and determination of hydrazine. Zeolite $L$ nanoparticles were synthesized via hydrothermal approach and then characterized using various techniques such as X-ray diffraction (XRD), Fourier transform infrared (FTIR), scanning electronic microscopy (SEM) and Brunauer-Emmett-Teller (BET). Silver-exchanged nanozeolite $\mathrm{L}(\mathrm{Ag} / \mathrm{L})$ was prepared and mixed with carbon paste to prepare the modified electrode. Cyclic voltammetry studies revealed the high performance of $\mathrm{Ag} / \mathrm{L}-\mathrm{CPE}$ for electrocatalytic oxidation of hydrazine. Two linear ranges were detected in the amperometric detection of hydrazine. The first range was from $10 \mu \mathrm{M}$ to $0.4 \mathrm{mM}$ with sensitivity of $103.13 \mu \mathrm{Am}^{-1}$ and the second one was from 0.4 to $4 \mathrm{mM}$ with sensitivity of $58.131 \mu \mathrm{A} \mathrm{mM}^{-1}$. The response time and detection limit $(S / N=3)$ of this sensor were determined to be $2 \mathrm{~s}$ and $1.5 \mu \mathrm{M}$, respectively. The unique porous structure of nanozeolite $\mathrm{L}$ offers a promising catalyst support candidate for efficient electrochemical sensing of hydrazine. The sensor exhibited appreciable repeatability, reproducibility and stability, and was able to detect hydrazine in the presence of even $\mathbf{5 0 0 - f o l d ~ e x c e s s ~ c o n c e n t r a t i o n s ~ o f ~ i n t e r f e r i n g ~}$ species. Also, the sensor was used to determine hydrazine concentration in water samples with satisfactory results.
\end{abstract}

Keywords. Zeolite L nanoparticles; silver ions; electrocatalytic oxidation; hydrazine; amperometric sensor.

\section{Introduction}

Hydrazine $\left(\mathrm{N}_{2} \mathrm{H}_{4}\right)$ is a small colourless inorganic molecule with a wide variety of applications in many fields such as industry, agriculture, pharmacy and fuel cells [1-3]. However, it is an extremely toxic and carcinogenic material. It has also been recognized as a neurotoxic and mutagenic compound and can cause different problems for human health such as the liver, brain, kidney [4] and DNA damages [5], blood abnormalities and irreversible deterioration of nervous system [6]. Wide industrial and pharmaceutical applications of hydrazine make it enter to the environment. The Environmental Protection Agency (EPA) has reported hydrazine as an environmental pollutant with a maximum recommended value in effluents set to $1.0 \mathrm{ppm}$ [7]. Hence, accurate, reliable and economical determination of hydrazine is an interesting field of research in analytical chemistry. To date, several methods have been reported for the determination of hydrazine such as spectrophotometry [8], amperometry [9], potentiometry [5], titrimetry [10], chemiluminescence [11] and ion chromatography [12]. Among these methods, electrochemical techniques are more preferred because they have many advantages such as cost-effectiveness, ease of fabrication, simple operation and high sensitivity and selectivity. However, the major barrier to the direct electrochemical

*Author for correspondence (azizi@umz.ac.ir) determination of hydrazine is the high overpotential requirement at the surfaces of bare electrodes. An efficient approach to enhance the electron transfer rate and overcome the high overpotential problem is the modification of electrode surfaces with catalytic materials [13-20]. Noble metals such as platinum [21,22], palladium [23,24], silver [25,26] and gold [27,28] are very active in the anodic oxidation of hydrazine. Among them, silver exhibits the highest electrical conductivity. It is also found to be highly biocompatible and cost-effective $[29,30]$.

The electrocatalytic activity of noble metals could be increased much more by preparing highly dispersed supported noble metal catalysts with the aid of porous materials such as zeolites. Synthesis of zeolites made large advances with the development of catalytic materials. Zeolites are microporous crystalline aluminosilicate compounds consisting of open framework structures and exchangeable cations that have great potential as catalysts, catalyst supports, sorbents and ion exchangers [31-36]. Especially zeolite L is known as a highly active catalyst support due to its unique structural features. It has hexagonal crystalline structure and contains one-dimensional channels that run parallel to the $c$-axis of hexagonal crystals [37,38]. The presence of wellarranged pores with aperture diameter of around 7.1 $\AA$ makes zeolite $\mathrm{L}$ an excellent candidate for hosting several different types of guests. Zeolite L could be synthesized in the absence of costly organic structure-directing agents (OSDAs), which is desirable due to economic considerations. 
In comparison with the dimensions of the zeolite micropores $(<2 \mathrm{~nm})$, mesopores $(2-50 \mathrm{~nm})$ allow faster migration of guest molecules in the host frameworks [39]. Hence generation of mesopores inside zeolite $\mathrm{L}$ particles results in reduced diffusional limitations and enhanced catalytic activities. Also, the size and morphology of zeolite L can affect its catalytic performances. Compared with microsized zeolite, nanosized zeolite exhibits enhanced properties such as increased surface area, decreased diffusion path lengths and presence of more pore entrances per weight amount of zeolite, which result in enhanced diffusion rates and reactivities $[40,41]$. Hence, synthesis of nanosized zeolite L crystals with short channel length as well as with low aspect ratio is highly desired when used as catalyst support.

In this work, we report for the first time the application of nanozeolite $\mathrm{L}$ for fabrication of a novel high-performance hydrazine sensor. Nanozeolite L was synthesized under hydrothermal conditions in the absence of costly OSDAs and was loaded with silver ions via simple ion exchange process. The modified electrode was then fabricated by modifying carbon paste electrode with Ag-doped nanozeolite L and was applied successfully to the electrocatalytic oxidation and determination of hydrazine.

\section{Experimental}

\subsection{Materials and method}

Silicic acid, graphite powder and sodium hydroxide were purchased from Merck. Aluminium foil, potassium hydroxide, silver nitrate and hydrazine were provided from Fluka.

In order to characterize nanozeolite L structure, X-ray diffraction (XRD) pattern was recorded on an X-ray diffractometer (SHIMADZUXD-DL) using $\mathrm{Cu} \mathrm{K}_{\alpha}$ radiation $(\lambda=$ $1.5418 \AA$ ). Fourier transform infrared (FT-IR) spectrum was recorded with a FT-IR spectrometer (Tensor 27-Bruker) at room temperature in the range of $400-1300 \mathrm{~cm}^{-1}$.

The size and morphology of the synthesized nanozeolite were investigated using scanning electron microscopy (SEM;
EM-3200, KYKY). Nitrogen physisorption isotherms were measured at $77 \mathrm{~K}$ using a Quantachrome NovaWin2 apparatus. Energy-dispersive X-ray (EDX) analysis of silver modified zeolite was carried out using a VEGA \\TESCAN-LMU scanning electron microscope.

All electrochemical experiments were performed using a Dropsens bipotentiostat/galvanostat ( $\mu$ STAT 400). An $\mathrm{Ag}|\mathrm{AgCl}| \mathrm{KCl}(3 \mathrm{M})$ electrode, a platinum wire and silverdoped nanozeolite-L-modified carbon paste electrode $(\mathrm{Ag} / \mathrm{L}-$ $\mathrm{CPE}$ ) were used as reference, auxiliary and working electrodes, respectively.

\subsection{Synthesis of nanozeolite $L$}

The following gel composition was used for the synthesis of nanozeolite $\mathrm{L}$ under hydrothermal conditions: $10 \mathrm{~K}_{2} \mathrm{O}: 20$ $\mathrm{SiO}_{2}: 1 \mathrm{Al}_{2} \mathrm{O}_{3}: 400 \mathrm{H}_{2} \mathrm{O}$ [42]. The silica solution was prepared by dissolving silicic acid $(20 \mathrm{mmol})$ in $\mathrm{KOH}$ solution $(3 \mathrm{M})$. Then, the prepared silica solution was added dropwise to alumina solution (prepared by dissolving aluminium foil in $\mathrm{KOH}$ solution) under vigorous stirring to form aluminosilica gel. The gel was transferred into a Teflon-lined stainless steel autoclave and heated at $170^{\circ} \mathrm{C}$ for 2 days. The resulting nanoparticles were then centrifuged, washed with deionized water and dried at $80^{\circ} \mathrm{C}$.

\subsection{Preparation of working electrode}

To prepare Ag-loaded nanozeolite $\mathrm{L}(\mathrm{Ag} / \mathrm{L}), 0.3 \mathrm{~g}$ of nanozeolite was stirred with $15 \mathrm{ml}$ of $0.1 \mathrm{M} \mathrm{AgNO}_{3}$ solution for $3 \mathrm{~h}$ in the absence of light. The cations present in nanozeolite $\mathrm{L}$ (potassium ions) can be exchanged with silver ions. Then, the prepared modified zeolite was centrifuged, washed with deionized water and dried in an oven at $70^{\circ} \mathrm{C}$ for $8 \mathrm{~h}$. For construction of $\mathrm{Ag} / \mathrm{L}-\mathrm{CPE}, 0.3 \mathrm{~g}$ of $\mathrm{Ag} / \mathrm{L}, 0.7 \mathrm{~g}$ of graphite powder and appropriate amount of paraffin were blended by hand mixing with a mortar and a pestle. The resulting paste was packed into the end of a glass tube (with internal radius $1.5 \mathrm{~mm}$ ). The electrical connection was implemented by a copper wire lead fitted into the glass tube. Finally, the

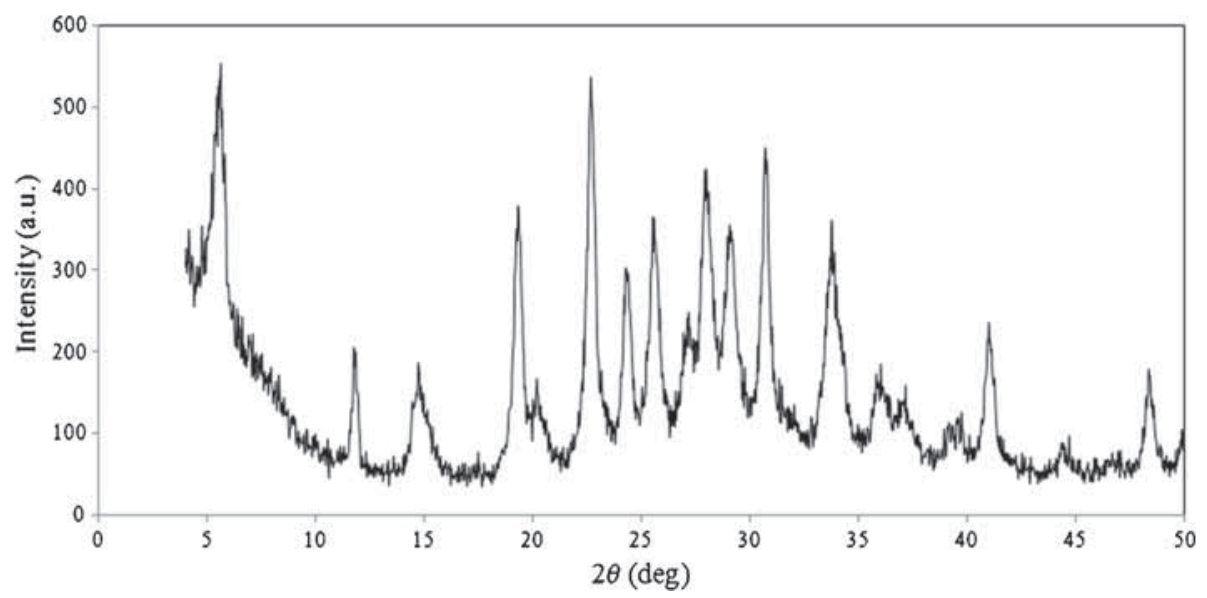

Figure 1. XRD pattern of zeolite L nanoparticles. 


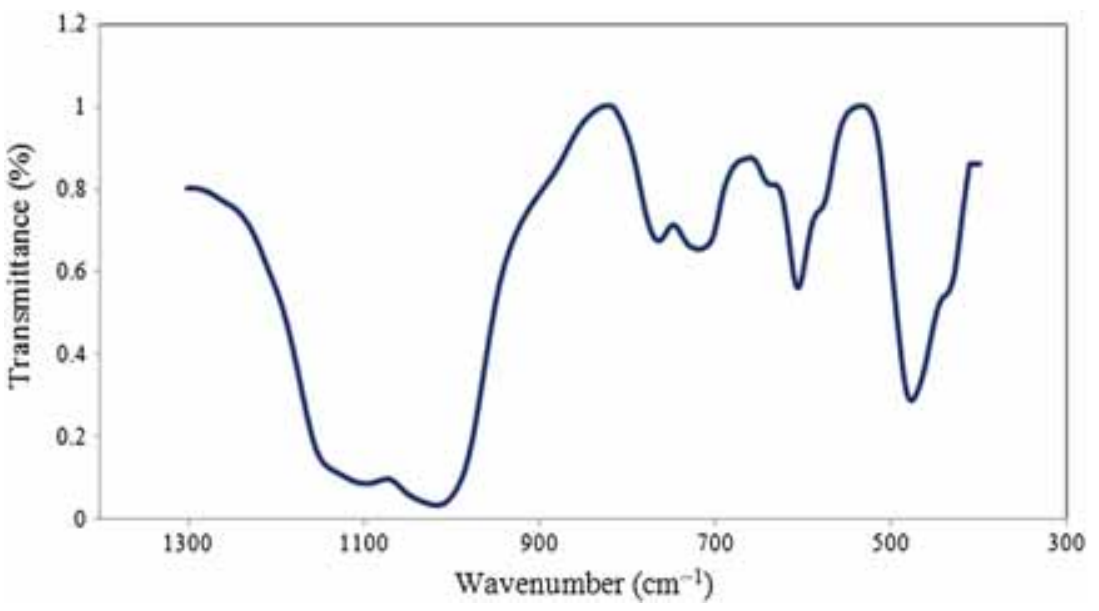

Figure 2. FT-IR spectrum of zeolite L nanoparticles.

constructed electrode was immersed in $0.1 \mathrm{M} \mathrm{AgNO}_{3}$ solution for $10 \mathrm{~min}$. Then, $\mathrm{Ag} / \mathrm{L}-\mathrm{CPE}$ was washed with deionized water to remove surface-adsorbed species. To investigate the role of nanozeolite $\mathrm{L}$ in electrocatalytic oxidation of hydrazine, L-CPE was constructed by the addition of nonmodified nanozeolite L to CPE. Also, blank experiments were carried out at $\mathrm{CPE}$ and $\mathrm{Ag} / \mathrm{CPE}$ to study the electrocatalytic behaviour of $\mathrm{Ag} / \mathrm{L}-\mathrm{CPE}$ on oxidation of hydrazine.

\section{Results and discussion}

\subsection{Characterization of nanozeolite $L$}

The XRD pattern of synthesized nanozeolite is shown in figure 1 . The figure shows the characteristic lines of nanozeolite $\mathrm{L}$ with good agreement to the XRD pattern of nanozeolite $\mathrm{L}$ in the literature [43].

Figure 2 shows the FT-IR spectrum of the sample in the range of $400-1300 \mathrm{~cm}^{-1}$. The broad band in the range 1008$1145 \mathrm{~cm}^{-1}$ is related to the asymmetric stretching vibrations of $\mathrm{O}-\mathrm{T}-\mathrm{O}(\mathrm{T}=\mathrm{Si}, \mathrm{Al})$ tetrahedral. The symmetric stretching vibrations of $\mathrm{O}-\mathrm{T}-\mathrm{O}$ tetrahedral have a band near $721 \mathrm{~cm}^{-1}$ and the symmetric stretching vibrations of $\mathrm{AlO}_{4}$ tetrahedral have a band near $765 \mathrm{~cm}^{-1}$. The band near $605 \mathrm{~cm}^{-1}$ is assigned to the vibration of double six-membered rings (D6Rs) and the band around $476 \mathrm{~cm}^{-1}$ belongs to the O-T-O bending vibrations [44].

SEM image of nanozeolite L (figure 3) reveals that agglomerated spherical-like nanoparticles of zeolite L with diameter in the range of $40-70 \mathrm{~nm}$ are formed.

Figure $4 \mathrm{a}$ shows the nitrogen adsorption/desorption isotherms of nanozeolite L. It shows a typical type IV structure and a hysteresis loop between the adsorption and desorption branches that could be regarded as a $\mathrm{H}_{1}$-type hysteresis loop. This type of hysteresis loop is found only in welldefined cylindrical pores or in material agglomerates consisting of extremely uniform particles [45]. The specific surface area and pore volume of zeolite nanoparticles obtained are $215 \mathrm{~m}^{2} \mathrm{~g}^{-1}$ and $0.4 \mathrm{cc} \mathrm{g}^{-1}$, respectively. Also, the pore size
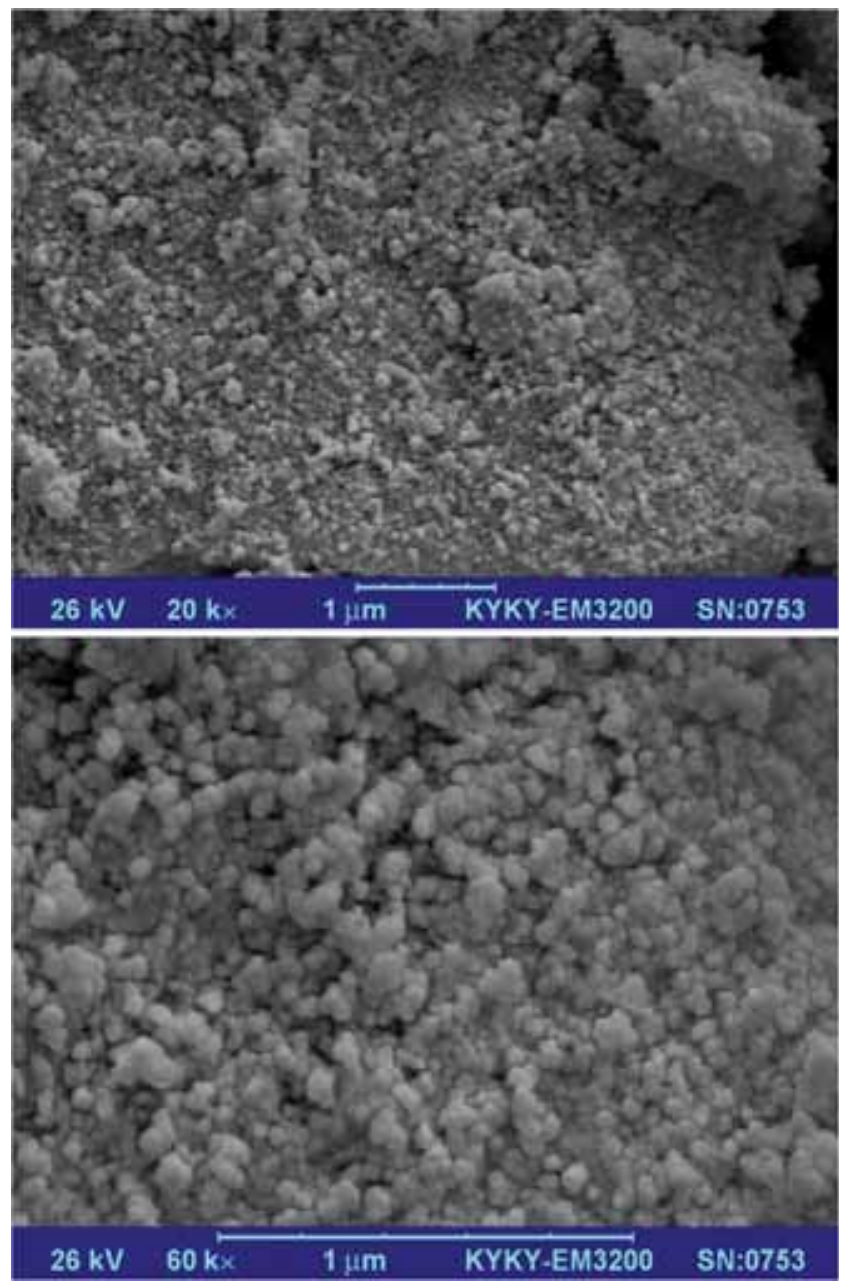

Figure 3. SEM images of nanozeolite $\mathrm{L}$ at different magnifications.

distribution of nanozeolite $\mathrm{L}$ is centred at about $3.65 \mathrm{~nm}$ (figure $4 b$ ).

EDX analysis of Ag-doped nanozeolite $\mathrm{L}$ is presented in figure 5. It shows that the modified nanozeolite consists of oxygen $(\mathrm{O})$, aluminium $(\mathrm{Al})$, silicon $(\mathrm{Si})$, potassium $(\mathrm{K})$ and 
silver $(\mathrm{Ag})$ with the weight percentages of $40.52,8.68,24.73$, 9.35 and 16.72 , respectively. The results confirm that silverexchanged nanozeolite $\mathrm{L}$ is successfully prepared.

\subsection{Electrochemical behaviour of $A g / L-C P E$ electrode}

Cyclic voltammetry was used to investigate the electrocatalytic behaviour of $\mathrm{Ag} / \mathrm{L}-\mathrm{CPE}$ towards the oxidation of
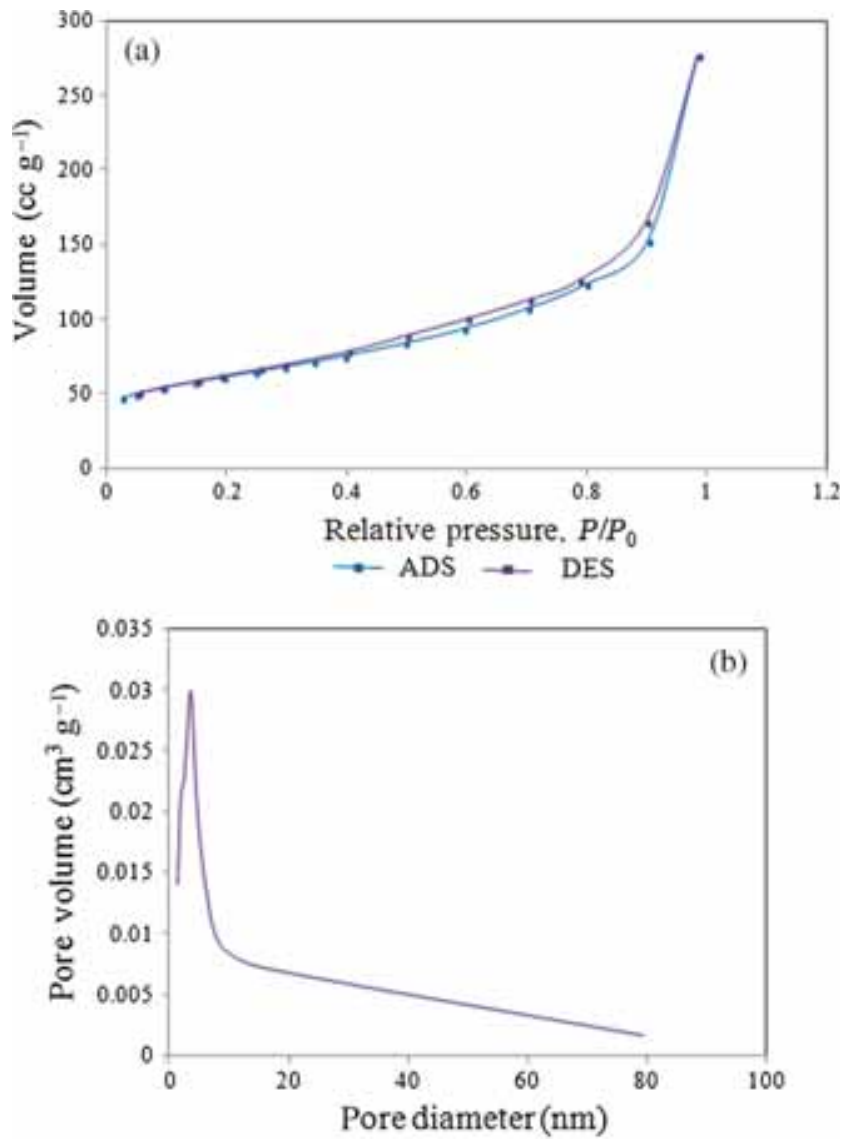

Figure 4. (a) Nitrogen adsorption desorption isotherms and (b) pore size distribution of nanozeolite L. hydrazine in alkaline media. Figure 6 displays electrochemical responses of (A) nonmodified $\mathrm{CPE}$ and (B) $\mathrm{Ag} / \mathrm{L}-\mathrm{CPE}$ in the (a) absence and (b) presence of $2 \mathrm{mM}$ hydrazine in $0.1 \mathrm{M}$ $\mathrm{NaOH}$ solution at a scan rate of $0.05 \mathrm{~V} \mathrm{~s}^{-1}$. As can be seen in the figure, no obvious peak is observed in the absence of hydrazine at the surface of both electrodes. In the presence of $2 \mathrm{mM}$ hydrazine an intensive oxidation peak is detected at $\mathrm{Ag} / \mathrm{L}-\mathrm{CPE}$ but no clear peak is observed at CPE. This evidence proves that the high catalytic performance of $\mathrm{Ag} / \mathrm{L}-$ CPE in hydrazine oxidation arises from the presence of silver active sites on the surface of modified electrode, where electrocatalytic process is carried out in alkaline media.

For further investigation of the role of modified electrode in oxidation of hydrazine, cyclic voltammograms of the bare $\mathrm{CPE}, \mathrm{Ag} / \mathrm{CPE}, \mathrm{L}-\mathrm{CPE}$ and $\mathrm{Ag} / \mathrm{L}-\mathrm{CPE}$ were recorded in the solution containing $2 \mathrm{mM}$ hydrazine in $0.1 \mathrm{M} \mathrm{NaOH}$ at the scan rate of $0.05 \mathrm{~V} \mathrm{~s}^{-1}$. As can be seen in figure 7 , no obvious voltammetric response was observed at (a) CPE and (b) L$\mathrm{CPE}$, while a small oxidation peak appeared around $-0.05 \mathrm{~V}$ on the surface of (c) $\mathrm{Ag} / \mathrm{CPE}$ due to oxidation of hydrazine. These observations show that nanozeolite L has no significant role in the oxidation of hydrazine, and the presence of silver ions in CPE is necessary for the oxidation process. In comparison with $\mathrm{Ag} / \mathrm{CPE}$, a considerable increase in oxidation peak current could be observed on $\mathrm{Ag} / \mathrm{L}-\mathrm{CPE}$ (figure 7d). This observation could be attributed to the presence of nanozeolite $\mathrm{L}$ in the structure of modified electrode. Although nanozeolite $\mathrm{L}$ is a nonconductive material and cannot contribute to increasing of the oxidation current alone, its porous structure provides a high surface area for $\mathrm{Ag}^{+}$ions uptake. Hence, more active sites are available on the surface of $\mathrm{Ag} / \mathrm{L}-\mathrm{CPE}$ and the oxidation peak current increases in comparison with $\mathrm{Ag} / \mathrm{CPE}$.

Figure 8 shows the effect of hydrazine concentration on the voltammetric response of $\mathrm{Ag} / \mathrm{L}-\mathrm{CPE}$. As can be seen, the voltammetric response of $\mathrm{Ag} / \mathrm{L}-\mathrm{CPE}$ increases with the increment of hydrazine concentration, which affirms the high catalytic activity of the modified electrode in various concentrations of hydrazine.

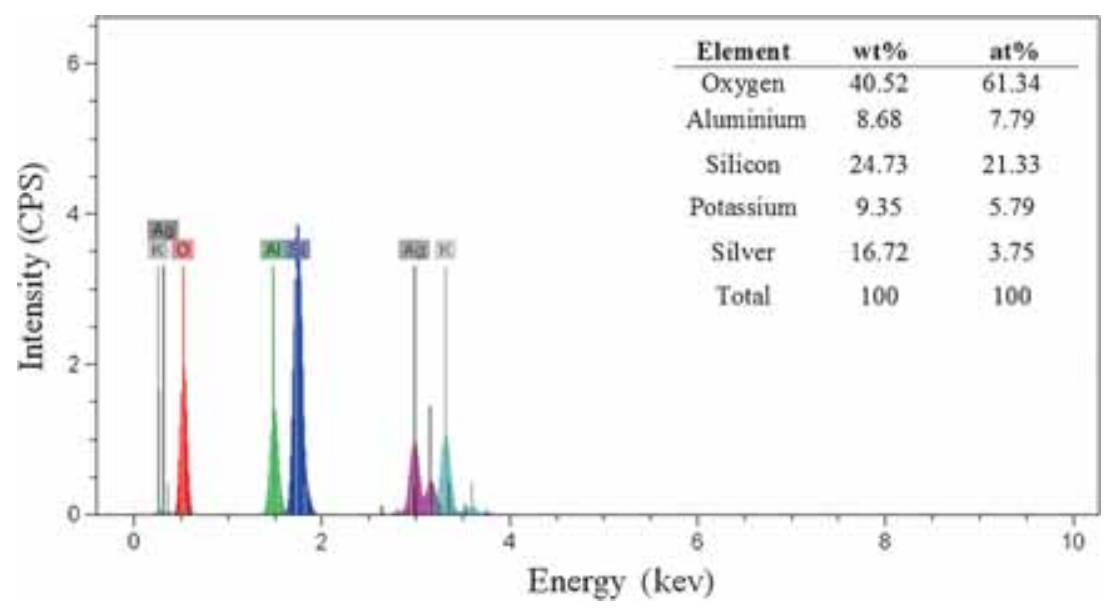

Figure 5. EDX analysis of Ag-doped nanozeolite L. 


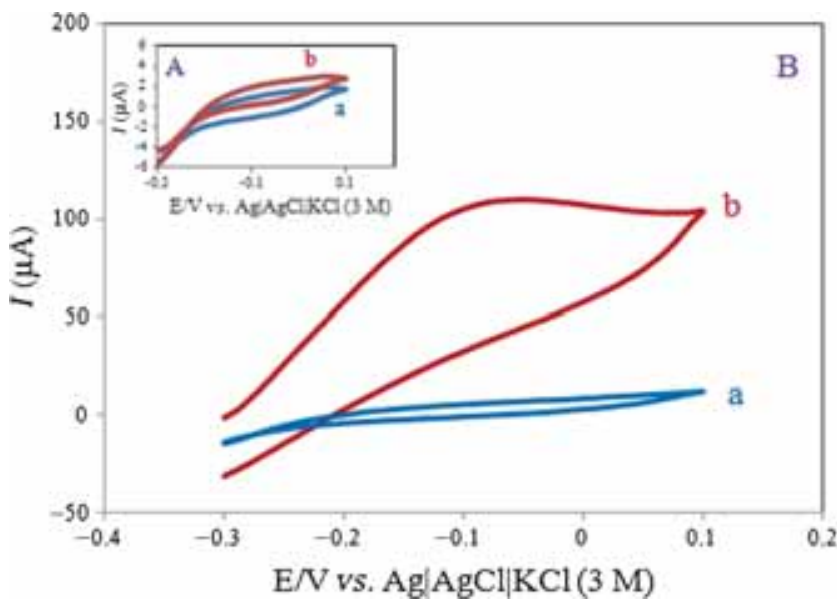

Figure 6. Cyclic voltammograms of (A) $\mathrm{CPE}$ and (B) $\mathrm{Ag} / \mathrm{L}-\mathrm{CPE}$ in the (a) absence and (b) presence of $2.0 \mathrm{mM} \mathrm{N}_{2} \mathrm{H}_{4}$ in $0.1 \mathrm{M} \mathrm{NaOH}$ solution at scan rate of $0.05 \mathrm{~V} \mathrm{~s}^{-1}$.

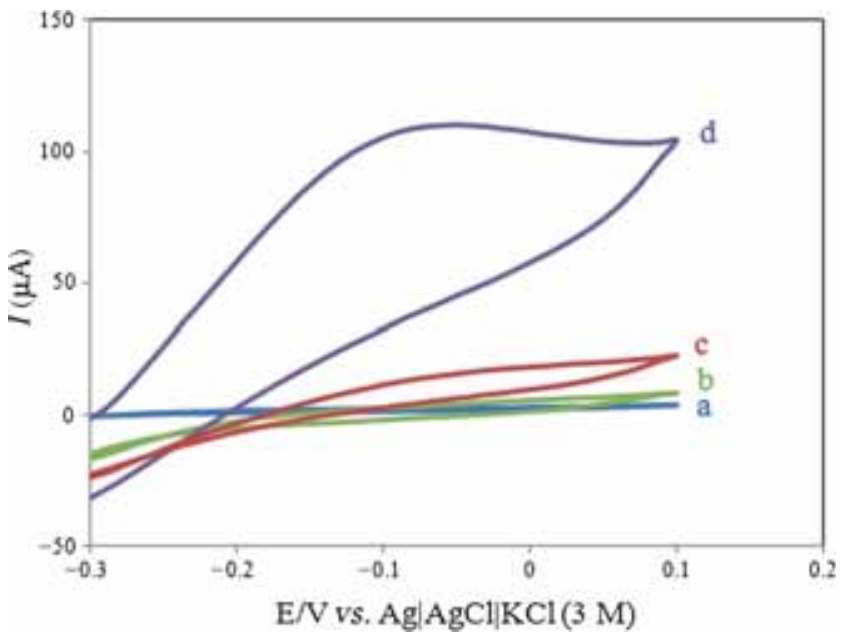

Figure 7. Cyclic voltammograms of (a) L-CPE and (b) $\mathrm{Ag} / \mathrm{L}-$ $\mathrm{CPE}$ in $0.1 \mathrm{M} \mathrm{NaOH}$ solution in the presence of $2.0 \mathrm{mM} \mathrm{N}_{2} \mathrm{H}_{4}$ at scan rate of $0.05 \mathrm{~V} \mathrm{~s}^{-1}$.

The effect of scan rate on the anodic peak current of $2 \mathrm{mM}$ hydrazine at $\mathrm{Ag} / \mathrm{L}-\mathrm{CPE}$ in $0.1 \mathrm{M} \mathrm{NaOH}$ solution is shown in figure 9. The linear relationship between anodic peak currents and square roots of scan rates indicates the diffusion-controlled nature of the oxidation process (inset).

\subsection{Amperometric determination of hydrazine}

Figure 10a represents the amperometric response of $\mathrm{Ag} / \mathrm{L}-$ $\mathrm{CPE}$ to the consecutive additions of hydrazine to the stirred $0.1 \mathrm{M} \mathrm{NaOH}$ solution at an applied potential of $-0.05 \mathrm{~V} v s$. $\mathrm{Ag} \mid \mathrm{AgCl}$. As can be seen in the figure the sensor shows fast amperometric response and could achieve $95 \%$ of the steady state current within $2 \mathrm{~s}$.

The corresponding calibration plot (figure 10b) shows that the current response and the hydrazine concentration have a linear relationship in the ranges of $10 \mu \mathrm{M}-0.4 \mathrm{mM}(1.6$

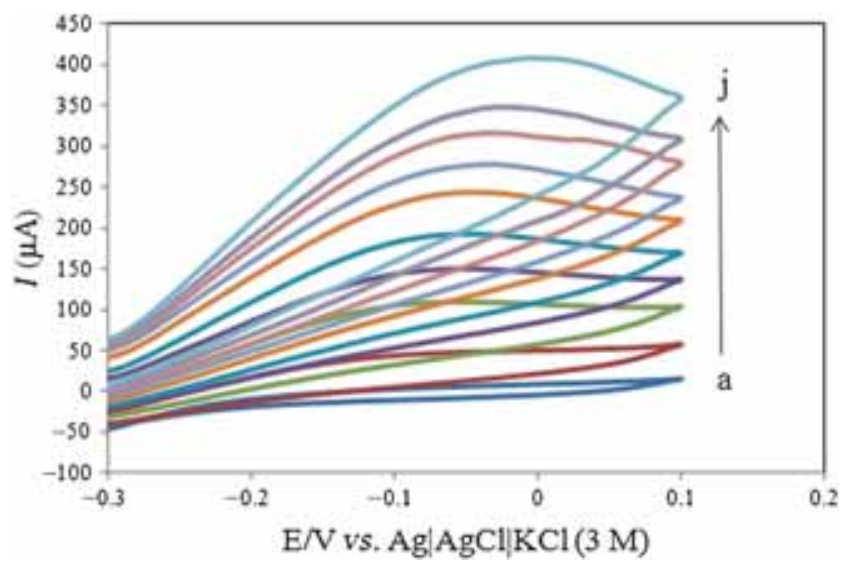

Figure 8. Cyclic voltammograms of $\mathrm{Ag} / \mathrm{L}-\mathrm{CPE}$ in $0.1 \mathrm{M} \mathrm{NaOH}$ solution containing different concentrations of $\mathrm{N}_{2} \mathrm{H}_{4}$ : (a) 0 , (b) 1 , (c) 2, (d) 3, (e) 4, (f) 6, (g) 8, (h) 10, (i) 12 and (j) $14 \mathrm{mM}$ at scan rate of $0.05 \mathrm{~V} \mathrm{~s}^{-1}$.

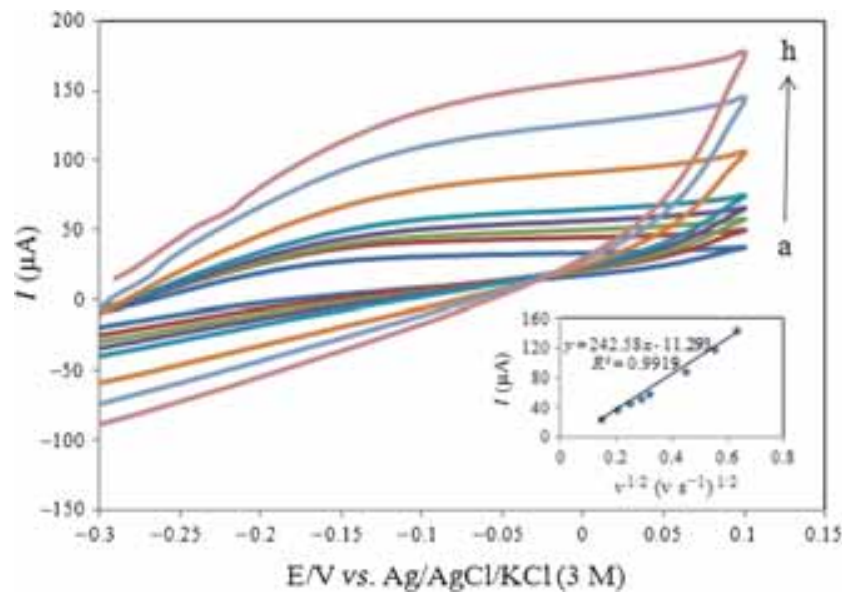

Figure 9. Cyclic voltammograms of $\mathrm{Ag} / \mathrm{L}-\mathrm{CPE}$ in the presence of $2.0 \mathrm{mM} \mathrm{N}_{2} \mathrm{H}_{4}$ in $0.1 \mathrm{M} \mathrm{NaOH}$ solution at different scan rates: (a) 0.02 , (b) 0.04 , (c) 0.06 , (d) 0.08 , (e) 0.1 , (f) 0.2 , (g) 0.3 and (h) $0.4 \mathrm{~V} \mathrm{~s}^{-1}$. Inset: Plot of oxidation peak current of hydrazine vs. $v^{1 / 2}$.

order of magnitude) and $0.4-4 \mathrm{mM}$ (1 order of magnitude). Also, high sensitivities of 103.13 and $58.131 \mu \mathrm{A} \mathrm{mM}^{-1}$ and a low detection limit of $1.5 \mu \mathrm{M}(S / N=3)$ are achieved. Two different slopes at $\mathrm{Ag} / \mathrm{L}-\mathrm{CPE}$ electrode indicate the change in oxidation kinetics of hydrazine due to the production of molecular nitrogen bubbles on the catalytic active sites [46-51]. At low hydrazine concentrations the number of $\mathrm{N}_{2}$ bubbles formed is low and does not affect the diffusion of new analyte molecules to the electrode surface. When hydrazine concentration increases, the $\mathrm{N}_{2}$ generated at the surface affects the normal diffusion of new hydrazine molecules to the surface, resulting in decay in the sensitivity of the linear response.

The analytical performances of $\mathrm{Ag} / \mathrm{L}-\mathrm{CPE}$ are summarized in table 1 and compared to some other $\mathrm{N}_{2} \mathrm{H}_{4}$ sensors. The data reported in the table indicate that $\mathrm{Ag} / \mathrm{L}-\mathrm{CPE}$ 

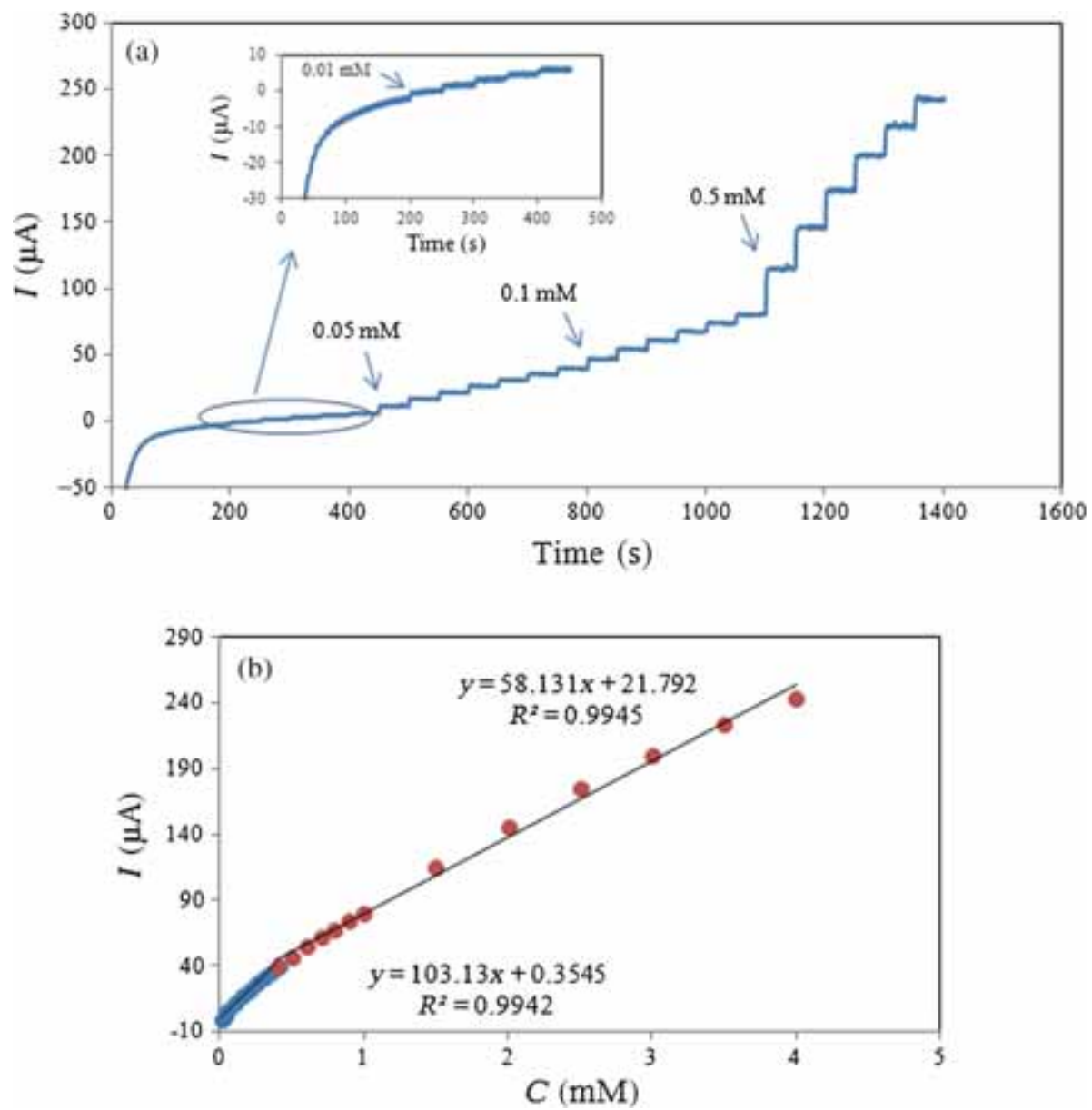

Figure 10. (a) Typical amperometric response of the Ag/L-CPE to successive injections of $\mathrm{N}_{2} \mathrm{H}_{4}$ into the stirred $\mathrm{N}_{2}$-saturated $0.1 \mathrm{M} \mathrm{NaOH}$ solution, applied potential: $-0.05 \mathrm{~V}$ vs. $\mathrm{Ag} \mid \mathrm{AgCl}$. (b) Calibration curve of electrocatalytic oxidation peak current of $\mathrm{N}_{2} \mathrm{H}_{4}$ vs. its concentration.

Table 1. Comparison of several typical $\mathrm{N}_{2} \mathrm{H}_{4}$ sensors.

\begin{tabular}{|c|c|c|c|c|c|}
\hline Sensors & Method & $\begin{array}{c}\text { Applied } \\
\text { potential }(\mathrm{V})\end{array}$ & $\begin{array}{c}\text { Linear } \\
\text { range }(\mathrm{mM})\end{array}$ & $\begin{array}{l}\text { Detection } \\
\text { limit }(\mu \mathrm{M})\end{array}$ & Reference \\
\hline $\mathrm{Ag} / \mathrm{CB}-\mathrm{GCE}$ & Chronoamperometry & 0.4 & $0.05-0.8$ & 3.47 & {$[52]$} \\
\hline $\mathrm{Pd} / \mathrm{CNF}-\mathrm{GCE}$ & Differential pulse voltammetry & -0.32 & $0.01-4$ & 2.9 & {$[53]$} \\
\hline $\mathrm{Au} /$ porous- $\mathrm{TiO}_{2} / \mathrm{GCE}$ & Amperometry & 0.2 & $0.0025-0.5$ & 0.5 & {$[54]$} \\
\hline $\mathrm{CoOOH}$ nanosheet & Amperometry & 0.1 & $0.01-2$ & 20 & [55] \\
\hline Pd-plated BDD microdisc array & Linear sweep voltammetry & 0.16 & $0.01-0.102$ & 1.8 & [56] \\
\hline $\mathrm{Au} / \mathrm{Ti}$ & Cyclic voltammetry & -0.55 & $5-40$ & 42 & [57] \\
\hline $\mathrm{BiHCF} / \mathrm{CCE}$ & Amperometry & 0.3 & $0.007-1.100$ & 3 & {$[58]$} \\
\hline $\mathrm{PtNPs} / \mathrm{TiO}_{2} \mathrm{NSs} / \mathrm{GCE}$ & Chronoamperometry & 0.3 & $0.02-2.10$ & 2.0 & [59] \\
\hline Pd-nanowire-modified CILE & Square wave voltammetry & -0.02 & $0.005-0.8$ & 0.82 & {$[60]$} \\
\hline $\mathrm{Ag} / \mathrm{L}-\mathrm{CPE}$ & Amperometry & -0.05 & $0.01-4$ & 1.5 & This work \\
\hline
\end{tabular}

has comparatively appropriate applied potential, low detection limit and wide linear range. These advantages can be attributed to the cooperative effect of high surface area of nanozeolite $\mathrm{L}$ and considerable catalytic activity of $\mathrm{Ag}$ towards oxidation of hydrazine.

\subsection{Interference study}

To evaluate the selectivity of the proposed sensor in determination of hydrazine, the effects of some common electroactive interferences such as glucose, sucrose, $\mathrm{NO}_{3}^{-}, \mathrm{NO}_{2}^{-}$, 
$\mathrm{CH}_{3} \mathrm{COO}^{-}, \mathrm{SO}_{4}^{-}, \mathrm{Cl}^{-}, \mathrm{F}^{-}, \mathrm{NH}_{4}^{+}, \mathrm{Na}^{+}$and $\mathrm{K}^{+}$were examined (figure 11). It was observed that even the presence of 500-fold excess concentrations of interfering species could not interfere with the detection of hydrazine, which is largely attributed to the low applied potential of sensor.

\subsection{Repeatability, reproducibility and stability}

The repeatability and reproducibility of $\mathrm{Ag} / \mathrm{L}-\mathrm{CPE}$ were investigated for $0.5 \mathrm{mM}$ hydrazine in $0.1 \mathrm{M} \mathrm{NaOH}$ solution. To evaluate the repeatability of the sensor, 5 successive amperometric measurements were performed and an acceptable relative standard deviation (RSD) of $3.3 \%$ was calculated. Five electrodes were prepared using the same method to check the reproducibility of the sensor. The RSD of the amperometric measurements obtained was $4.5 \%$, indicating high reproducibility of the sensor. Also, the operational and storage stability of the proposed sensor were investigated. The operational stability of the sensor was examined by observing the change of amperometric response of the modified electrode to $\mathrm{N}_{2} \mathrm{H}_{4}$ in $0.1 \mathrm{M} \mathrm{NaOH}$. Figure 12 shows that the current response remains relatively stable after 1000 s. Furthermore, the sensor retained about $94 \%$ of its initial response to $\mathrm{N}_{2} \mathrm{H}_{4}$ after 2 weeks. These results indicate that the proposed sensor has appreciable operational and storage stability.

\subsection{Application to real sample analysis}

In order to evaluate the practicality of the sensor towards determination of hydrazine, water samples were collected from different sources and were employed for the real sample analysis (table 2). The samples were spiked with $100 \mu \mathrm{M}$ of hydrazine and were analysed. The satisfactory results

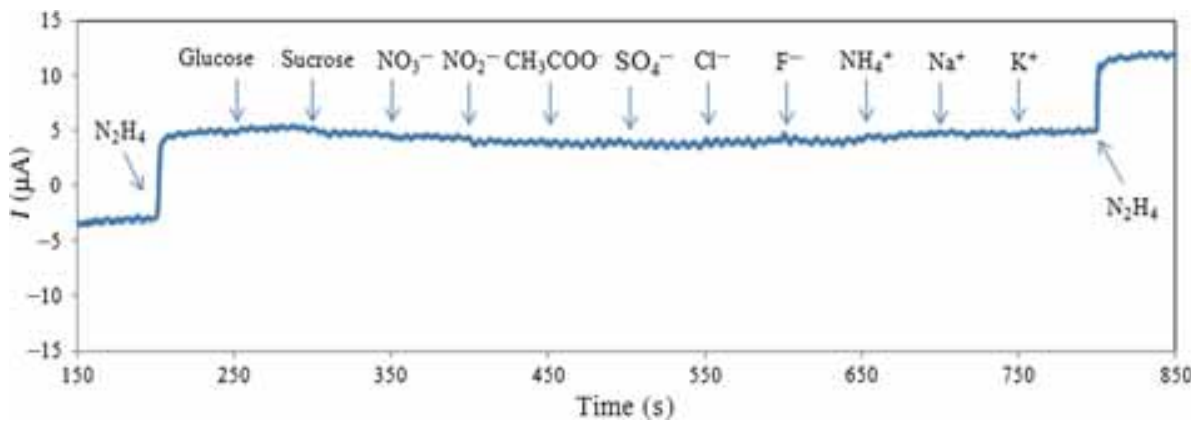

Figure 11. Amperometric responses of the $\mathrm{Ag} / \mathrm{L}-\mathrm{CPE}$ to $\mathrm{N}_{2} \mathrm{H}_{4}$ and different interfering substances at the applied potential of $-0.05 \mathrm{~V} v s$. $\mathrm{Ag} \mid \mathrm{AgCl}$ in a stirred $0.1 \mathrm{M} \mathrm{NaOH}$ solution.

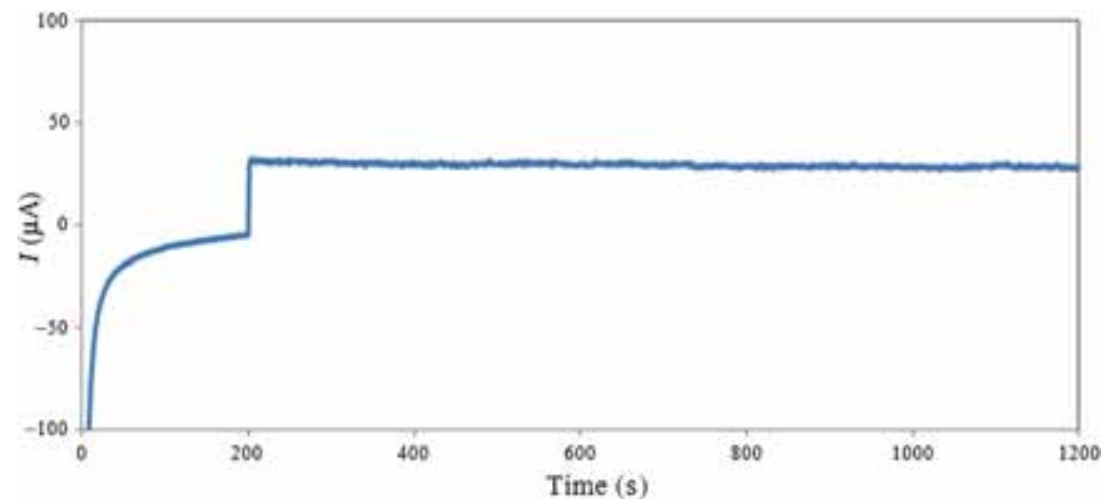

Figure 12. Amperometric response of $\mathrm{Ag} / \mathrm{L}-\mathrm{CPE}$ to $\mathrm{N}_{2} \mathrm{H}_{4}$ during $1000 \mathrm{~s}$ at the applied potential of $-0.05 \mathrm{~V} v s$. $\mathrm{Ag} \mid \mathrm{AgCl}$ in a stirred $0.1 \mathrm{M} \mathrm{NaOH}$ solution.

Table 2. Determination of hydrazine in water samples at $\mathrm{Ag} / \mathrm{L}-\mathrm{CPE}$.

\begin{tabular}{lcccc}
\hline Sample & Spiked $(\mu \mathrm{M})$ & Found $(\mu \mathrm{M})$ & RSD $(\%, n=3)$ & Recovery $(\%)$ \\
\hline Tap water & 100 & 96.33 & 4.68 & 96.33 \\
River water & 100 & 101.66 & 3.16 & 101.66 \\
Spring water & 100 & 98.33 & 4.23 & 98.33 \\
\hline
\end{tabular}


achieved in the determination of hydrazine in water samples revealed the practical feasibility of the proposed sensor towards determination of hydrazine.

\section{Conclusion}

Nanozeolite L was synthesized under hydrothermal conditions and its characterization confirmed the successful formation of nanoparticles of zeolite $\mathrm{L}$ with uniform mesopores. It was used as a novel and efficient catalyst support to develop a new sensor for hydrazine determination. Silver-supported nanozeolite L exhibits high catalytic activity towards electrooxidation of hydrazine. The high catalytic activity of $\mathrm{Ag} / \mathrm{L}$ can be attributed to the porous structure of nanozeolite L, which provides high surface area for formation of silver active sites. Low detection limit, wide linear range, high sensitivity and selectivity and appreciable repeatability, reproducibility, stability and practicality are some unique features that make this electrode a promising candidate for hydrazine determination.

\section{References}

[1] Liang Y, Zhou Y, Ma J, Zhao J, Chen Y, Tang Y and Lu T 2011 Appl. Catal. B 103388

[2] Farghaly T A, Abdallah M A and Abdel Aziz M R 2012 Molecules 1714625

[3] Yang H, Lu B, Guo L and Qi B 2011 J. Electroanal. Chem. 650171

[4] Vernot E H, MacEwen J D, Bruner R H, Haus C C and Kinkead E R 1985 Fundam. Appl. Toxicol. 51050

[5] Mo J W, Ogorevc B, Zhang X and Pihlar B 2000 Electroanalysis 1248

[6] Garrod S, Bollard M E, Nicholls A W, Connor S C, Connelly J, Nicholson J K and Holmes E 2005 Chem. Res. Toxicol. 18115

[7] Amlathe S and Gupta V K 1988 Analyst 1131481

[8] Safavi A, Abbasitabar F and Hormozi Nezhad M R 2007 Chem. Anal. (Warsaw) 52835

[9] Jayasri D and Sriman Narayanan S 2007 J. Hazard. Mater. 144348

[10] Budkuley J S 1992 Microchim. Acta 108103

[11] Safavi A and Karimi M A 2002 Talanta 58785

[12] Gilbert R and Rioux R 1984 Anal. Chem. 56106

[13] Swetha P, Devi K S S and Kumar A S 2014 Electrochim. Acta 14762

[14] Abbaspour A, Shamsipur M, Siroueinejad A, Kia R and Raithby P R 2009 Electrochim. Acta 542916

[15] Rastogi P K, Ganesan V and Krishnamoorthi S 2014 Electrochim. Acta 125593

[16] Jena B K and Raj C R 2007 J. Phys. Chem. C 1116228

[17] Zhou B, Yang J and Jiang X 2015 Mater. Lett. 159362

[18] Heydari H, Gholivand M B and Abdolmaleki A 2016 Mater. Sci. Eng. C 6616

[19] Zhao J, Lio J, Tricard S, Wang L, Liang Y, Cao L, Fang J and Shen W 2015 Electrochim. Acta 171121
[20] Eiaz A, Ahmed M S and Jeon S 2015 Sens. Actuators B 2211256

[21] Yin W X, Li Z P, Zhu J K and Qin H Y 2008 J. Power Sources 182520

[22] Yue X, Yang W, Xu M, Liu X and Jia J 2015 Talanta 1441296

[23] Dong B, He L, Huang J, Gao G Y, Yang Z and Li H L 2008 J. Power Sources 175266

[24] Kim S K, Jeong Y N, Ahmed M S, You J M, Choi H C and Jeon S 2011 Sens. Actuators B 153246

[25] Paulraj P, Janaki N, Sandhya S and Pandian K 2011 Colloids Surf. A 37728

[26] Wang Y, Yang X, Bai J, Jiang X and Fan G 2013 Biosens. Bioelectron. 43180

[27] Abdul Aziz M and Kawde A N 2013 Talanta 115214

[28] Li J, Xie H and Chen L 2011 Sens. Actuators B 153239

[29] Azizi S N, Ghasemi S and Salek Gilani N 2016 Monatsh. Chem. 1471467

[30] Sophia J and Muralidharan G 2014 Sens. Actuators B 193 149

[31] Azizi S N, Ghasemi S and Amiripoor F 2016 Sens. Actuators B 2271

[32] Wang W, Li R, Fan B, Ma J and Zhang R 2015 Ionics 212591

[33] Azizi S N, Ghasemi S and Salek Gilani N 2014 Chin. J. Catal. 35383

[34] Volli V and Purkait M K 2015 J. Hazard. Mater. 297101

[35] Garrido Pedrosa A M, Souza M J B, Melo D M A and Araujo A S 2006 Mater. Res. Bull. 411105

[36] Wang Y and Lin F 2009 J. Hazard. Mater. 1661014

[37] Yin X, Wang J, Chu N, Yang J, Lu J, Zhang Y and Yin D 2010 J. Membr. Sci. 348181

[38] Lee T, Saad B, Poh Nga E and Salleh B 2012 J. Chromatogr. A 123746

[39] Tao Y, Kanoh H, Abrams L and Kaneko K 2006 Chem. Rev. 106896

[40] Larsen S C 2007 J. Phys. Chem. C 11118464

[41] Van Donk S, Janssen A H, Bitter J H and de Jong K P 2003 Catal. Rev. Sci. Eng. 45297

[42] Holzl M, Mintova S and Bein T 2005 Stud. Surf. Sci. Catal. 1581

[43] Garces L J, Makwana V D, Hincapie B and Sacco A 2003 J. Catal. 217107

[44] Ko Y S and Ahn W S 1999 Bull. Korean Chem. Soc. 201

[45] Thommes M 2010 Chem. Ing. Tech. 821059

[46] Rastogi P K, Ganesan V and Krishnamoorthi S 2014 Electrochim. Acta 125593

[47] Yue X, Yang W, Xu M, Liu X and Jia J 2015 Talanta 1441296

[48] Ghanbari K 2014 Synth. Met. 195234

[49] Revenga-Parra M, Lorenzo E and Pariente F 2005 Sens. Actuators B 107678

[50] Li J, Xie H and Chen L 2011 Sens. Actuators B 153239

[51] Kamyabi M O, Narimani O and Hosseini Monfared H 2010 J. Electroanal. Chem. 64467

[52] Tan C, Xu X, Wang F, Li Z, Liu J and Ji J 2013 Sci. China Chem. 56911

[53] Zhang H, Huang J, Hou H and You T 2009 Electroanalysis 211869 
[54] Wang G, Zhang C, He X, Li Z, Zhang X, Wang L and Fang B 2010 Electrochim. Acta $\mathbf{5 5} 7204$

[55] Lee K K, Loh P Y, Sow C H and Chin W S 2013 Biosens. Bioelectron. 39255

[56] Batchelor-McAuley C, Banks C E, Simm A O, Jones T G J and Compton R G 2006 Analyst 131106
[57] Yi Q and Yu W 2009 J. Electroanal. Chem. 633159

[58] Zheng J, Sheng Q, Li L and Shen Y 2007 J. Electroanal. Chem. $\mathbf{6 1 1} 155$

[59] Yue X, Yang W, Xu M, Liu X and Jia J 2015 Talanta 1441296

[60] Maleki N, Safavi A, Farjami E and Tajabadi F 2008 Anal. Chim. Acta 611151 